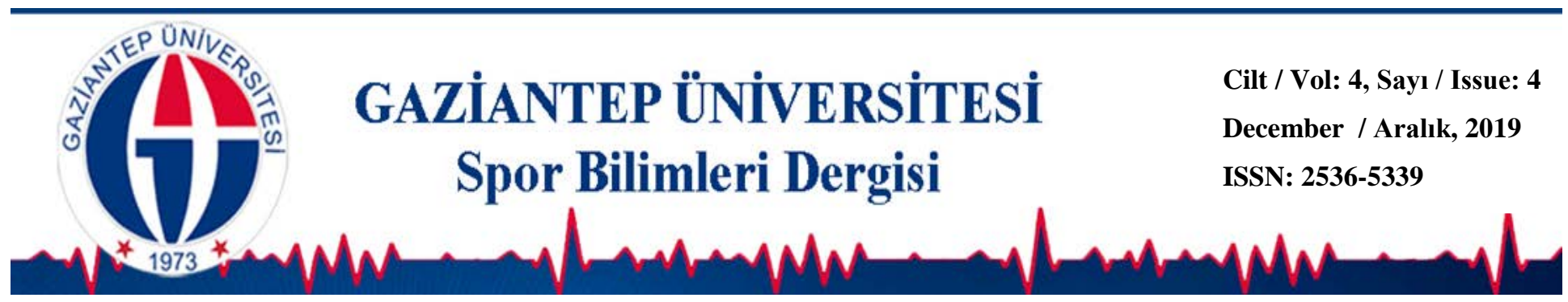

\title{
Down Sendromlu Gençlerin Fiziksel Uygunluk Düzeylerinin Normal Gelişim \\ Gösteren Akranları İle Karşılaştırılarak İncelenmesi
}

\author{
Ahmet SANSi ${ }^{1 *}$ (D) Dilara ÖZER ${ }^{2}$ iD \\ ${ }^{1}$ Batman Üniversitesi, Sağlık Hizmetleri MYO, BATMAN \\ ${ }^{2}$ İstanbul Kent Üniversitesi, Sağl1k Bilimleri Fakültesi, ISTANBUL
}

DOI: 10.31680/gaunjss.640772

Orijinal Makale / Original Article

Geliş Tarihi / Received: 31.10.2019 Kabul Tarihi / Accepted: 04.12.2019 Yayın Tarihi / Published: 18.12.2019

\section{Öz}

Bu araştırmada, Down Sendromlu (DS) ve normal gelişim gösteren (NGG) gençlerin fiziksel uygunluk düzeyleri

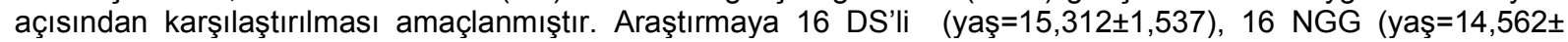
1,152) olmak üzere toplam 32 genç katılmıştır. Çalışmada nedensel karşılaştırma araştırma yöntemi kullanılmış olup veri toplama aracı olarak Brockport Fiziksel Uygunluk Testi uygulanmıştır. Bu test kapsamında Beden Kütle İndeksi (BKI), el kavrama kuvveti, mekik testi, omuz germe ve gövde kaldırma parametreleri ölçülmüştür. Araştırmada, SPS 21.0 programı ile iki grubun fiziksel uygunluk değerleri arasındaki farklılığı incelemek için Mann-Whitney U Testi uygulanmıştır. Araştırmaya katılan DS'li ve NGG gençler karşılaştırıldıklarında; BKI, el kavrama kuvveti, omuz germe ve mekik testi parametrelerinde istatistiksel olarak anlamlı düzeyde farklılık bulunmuştur $(p<.05)$. DS'li gençlerin akranları ile karşılaştırıldığında yüksek BKi değerlerine ve düşük fiziksel uygunluk seviyelerine sahip oldukları bulunmuştur. DS'li gençler için beden ağırlığı kontrolünün sağlanması ve fiziksel uygunluk düzeylerini artırmaya yönelik düzenli fiziksel aktivite programlarının uygulanması önerilmektedir. Anahtar Kelimeler: Down Sendromu, fiziksel uygunluk, beden kütle indeksi, el kavrama kuvveti.

\section{Examination of Physical Fitness Levels of Young People With Down Syndrome by Comparing Typical Development Peers}

\begin{abstract}
The aim of this study is to compare the physical fitness levels of young people with Down syndrome (DS) and typical development (TD). A total of 32 young people with 16 DS (age = 15,312 $\pm 1,537)$ and 16 TD (age $=14,562$ $\pm 1,152$ ) were included in the study. In the study, causal comparison research method was used and Brockport Physical Fitness Test was applied as data collection tool. Brockport Physical Fitness Test was used as a data collection tool. body mass index (BMI), hand grip strength, shuttle test, shoulder stretching and breast lifting parameters were measured within the scope of this test. In order to evaluate the results, Mann-Whitney $U$ Test was applied to examine the relationship between the two groups with SPSS 21.0 program. When compared with the DS and TD young people participating in the study; There were statistically significant differences in BMI, hand grip strength, shoulder stretching and shuttle test parameters $(p<.05)$. It was found that young people with DS had higher BMI values and lower physical fitness levels compared to their peers. It is recommended that regular physical activity programs should be implemented in order to provide body weight control and increase physical fitness levels for young people with DS.
\end{abstract}

Keywords: Down syndrome, physical fitness level, body mass index, hand grip force.

\footnotetext{
* Sorumlu Yazar: Ahmet Sansi
}

E-mail: cturkeri@cu.edu.tr 


\section{Giriş}

Down sendromu (DS) 21. kromozomda tam veya kısmi fazladan bir kromozom kopyası bulunması durumunda ortaya çıkan bir bozukluktur. Bu ek genetik materyal, gelişim sürecini değiştirir ve DS ile ilişkili özelliklere neden olur (National Down Syndrome Society, 2019).

Hastalıkları Önleme ve Kontrol Merkezinin (CDC) verilerine göre Amerika'da 700 çocuktan biri DS'li olarak doğmakta ve her yıl 6000 DS'li çocuk dünyaya gelmektedir. Ayrıca 1979 ve 2003 arasında, DS'li doğan bebek sayısı yaklaşık \% 30 arttığı bildirilmektedir (CDC, 2019).

Kromozomlarda görülen fazlalığının nedeni hala tam olarak bilinmemektedir. Anne yaşı, ayrışma veya mozaikleşme sonucu ortaya çıkan DS”li bir bebeğe sahibi olma olasılığını arttıran tek faktördür. Bununla birlikte, genç kadınlarda daha yüksek doğum oranları nedeniyle, 35 yaş altındaki kadınlar DS'li çocukların \% 80'ini dünyaya getirmektedir. Diğer taraftan DS'nin çevresel faktörler ile ebeveynlerin hamilelikten önce veya hamilelik sırasında yaptıkları faaliyetlerden kaynaklandığını gösteren kesin bir bilimsel araştırma yoktur. Ayrıca DS'ye neden olan 21. kromozomun kısmen veya tamamen kopyalanması anne veya babadan kaynaklanabilmektedir (National Down Syndrome Society, 2019).

DS'li olgular, Trizomi 21, Mozaizim ve Translokasyon olmak üzere 3 farklı tipte görülmektedir.

Regüler Trizomi (Serbest Trizomi): DS genellikle hücre bölünmesinde "bölünmeme" olarak adlandırılan bir hatadan kaynaklanır. Bölünmeme 21. kromozomda iki yerine üç kopya kromozomu içeren bir embriyo ile sonuçlanır. Gebe kalmadan önce veya gebe kalındığında, sperm veya yumurtadaki bir çift 21 . kromozom ayrılmaz. Embriyo geliştikçe, ekstra kromozom vücudun her hücresinde çoğaltılır. Vakaların\% 95'ini oluşturan bu tip DS, trizomi 21 olarak adlandırılır (National Down Syndrome Society, 2019).

Mozaik Tip: Mozaizm (veya mozaik DS), bazıları normal 46 kromozom içeren ve bazıları 47 içeren iki hücre tipi karışımı olduğunda teşhis edilir. 47 kromozomlu hücreler 21. kromozomda fazlalık görülür. Mozaizm, DS'nin en az görülen şeklidir ve DS vakalarının yalnızca \%1'ini oluşturur. Bununla birlikte mozaik tip DS'li bireyler, diğer DS'lilerden daha az DS özelliği taşımaktadır (National Down Syndrome Society, 2019).

Translokasyon Tip: DS vakalarının yaklaşık\% 4'ünü oluşturan translokasyonda, hücrelerdeki toplam kromozom sayısı 46; bununla birlikte, 21 . 
kromozomun tam veya kısmi bir kopyası genellikle 14. kromozoma yapışır. Fazla 21. kromozomun varlığı, DS özelliklerinin görülmesine neden olur (National Down Syndrome Society, 2019).

DS'de en yaygın görülen fiziksel özellikler; kısa boy, kısa kol ve bacaklar, gözlerin çekik olması, hipotoni, obezite, az gelişmiş solunum ve kalp damar sistemi, düzleşmiş yüz, zayıf denge, görme ve işitme problemleri olarak sıralanabilir. DS'lilerde bu özellikler farklı derecelerde görülmektedir (Winnick ve Porretta, 2016).

DS'li bireylerde zihinsel engel seviyesi değişmekle birlikte her çocukta görülen önemli bir sorundur (Cohen ve ark., 2003). Bununla birlikte zihinsel engel, azalmış motor yeteneğin de önemli sebeplerinden biridir (Lauteslager, 2004).

Hipotoni, tüm olgularda görülen ve gelişimi olumsuz etkileyen diğer bir önemli nörolojik bulgudur. Literatürde hipotoni, koordinasyon bozukluğu ve denge kaybı gibi motor bozuklukların nedeninin serebral korteksteki kıvrımların az olması, özellikle serebellum ve frontal lobla ilişkili nöronların myelinizasyonunun yetersiz olmasıyla ilişkili olduğu belirtilmektedir. DS'de görülen tipik motor gelişimle, doğumdan sonra sinaps sayılarının artması arasında doğru bir orantı olduğu düşünülmektedir. Bununla birlikte DS'li bireylerin kaba ve ince motor becerilerinin engelsiz bireylere kıyasla geri olduğu ve gelişimlerinin yavaş olduğu bilinmektedir (Cohen ve ark., 2003; Lauteslager, 2004) .

DS'li çocuklarda ilk aylarda ince motor gelişim, kaba motor gelişime paralel gelişir. İlerleyen yaşla birlikte ince motor becerilerdeki gerilik daha çok belirginleşir. İnce motor beceri gelişim için stabilizasyon, koordinasyon ve duyu algılarının koordineli bir şekilde gelişmesi gerekmektedir. Ayrıca DS'nin tipik özelliklerinden olan zihinsel engel, öğrenme bozuklukları ve bilgi kullanma bozuklukları gibi durumlar ince motor becerilerin gelişimini olumsuz etkiler. DS'li bireylerin kaba ve ince motor becerilerinde gelişim sağlanması, günlük yaşamda bağımsızlık kazanmaları açısından önem taşır. Bununla birlikte motor gelişimin geri olması, eğitimlerini ve sosyal ilişkilerini olumsuz etkiler (Jobling, 1998).

DS'li doğan tüm bebeklerin yaklaşık \% 50'si aynı zamanda doğuştan bir kalp hastalığı ile doğar. DS'li bebekler çok çeşitli kalp kusurlarından etkilenebilir. Bundan dolayı birçoğunun ameliyat olması gerekirken, bazı daha hafif kalp defektleri çocuk büyüdükçe kendiliğinden kaybolabilir ve yalnızca bir sağlık kuruluşu tarafından izlenmesine intiyaç duyulabilir (National Down Syndrome Society, 2019).

DS'li olguların \%10-20'sinde 2. servikal vertebrayla atlas arasında bulunan transvers ligamentte ve atlanto-oksipital eklemde gevşeklik görülür. Atlantoaksiyal 
instabilitenin kesin tanısı lateral vertebra grafisi ile konulur. Olguların \% 1-2'sinde omuriliğe baskı şeklinde belirtiler görülür (Ali ve ark., 2006).

Karşılaştıkları birçok tıbbi sorun nedeni ile DS'li çocukların fiziksel aktiviteye veya beden eğitimi programlarına katılımları tıbbi kontrol gerektirebilir. Aerobik ve maksimum kas kasılmasını gerektiren aktiviteler uyarlanarak dikkatli bir şekilde izlenmelidir. Kaslarda görülen hipotoni (düşük kas tonusu) ve hipermobilite (eklemlerde görülen hareketliliğin normalin üstünde olması) nedeni ile hiperfleksiyona (aşırı bükülme) neden olan egzersizler ve aktiviteler uygulanmamalıdır. Bunun yerine eklem çevresindeki kasları kuvvetlendiren egzersizler ve aktiviteler önerilmektedir (Winnick ve Porretta, 2016).

\section{Down Sendromlu Çocukların Gelişimsel Özellikleri}

Bilişsel özellikler: DS'li bireylerde çeşitli derecelerde zihinsel engel görülür Lauteslager, 2004; Schieve, 2009). Maatta ve ark. (2006) tarafından 121 DS'li çocuğun bilişsel becerilerinin değerlendirildiği bir çalışmada; olguların \% 19'unda hafif, \% 30'unda orta, \% 33'ünde ağır ve \% 18'inde ileri ağır derecelerde zihinsel engel görüldüğü ve yetişkinlerde görülen zihinsel engelin, gençlerde görülen zihinsel engele kıyasla daha ağır olduğu bildirilmiştir.

Psikomotor gelişim: DS'li bebeklerde değişen oranlarda ve zaman içerisinde azalan hipotoni, DS'ye özgü önemli diğer bir bulgudur ve yaşamın ilk 10 ayında en belirgin olarak görülür (Lauteslager, 2004). Hipotoninin ayrıca sindirim sistemindeki düz kasları da içine alan tüm kas gruplarını etkilediği; kaba ve ince motor becerilerde sebep olduğu geriliklerin yanında konstipasyon ve özofagiyal reflü gibi sorunların da nedeni olabileceği düşünülmektedir (Cohen ve ark., 2003).

Postüral kontrol, vücudun motor hareketler esnasında koordinasyonundan sorumlu sistemdir. Etkili bir postüral kontrol mekanizması; vücudun proksimal kısımlarının fiksasyonun sağlanmasının yanında, distal hareketlerin düzgün postür ve hareket örüntüleriyle, kontrollü olarak yapılmasının mümkün kılınmasını sağlar. DS'li çocuklarda denge bozuklukları, anormal hareket örüntüleri gibi hareket bozuklukları görülür. DS'li çocukların hareket kalitesi, zayıf kas tonusunun bir sonucu olan eklem stabilizasyonu eksikliğinden olumsuz olarak etkilenmekle birlikte motor becerilerin gelişmesi posüral tonusun artmasını sağlar. DS'nin tipik bulgularından olan gecikmiş motor gelişmeye, azalmış postüraltonus, yetersiz postüral reaksiyon, hipermobilite ve proprioseptif duyu kaybı eşlik eder. DS'li bireylerin motor gelişimleri üzerinde hipotoniye ilave eklem laksitesi, kısa ekstremiteler ve azalmış güç, zihinsel gelişim, 
sosyal gelişim ve genel sağlık sorunlarının yavaşlatıcı etkisi görülür. Ayrıca konjenital kalp hastalıkları ya da görme bozuklukları gibi sağlık problemlerinin de motor becerilerin gelişimini, bilişsel ve sosyal gelişimi etkilediği belirtilmiştir (Ali ve ark., 2006; Jobling, 1998; Lauteslager, 2004; Maatta ve ark., 2006; Winders, 1997).

\section{Fiziksel Uygunluk ve Fiziksel Aktivite}

Fiziksel uygunluk, günlük işleri canlı ve uyanık, yorgunluk duymaksızın, boş zamanlarını neşeli uğraşlar ile geçirebilecek gerekli enerjiye sahip ve beklenmeyen tehlikeleri karşılayabilecek yeterliliğe sahip olmak anlamını taşımaktadır (Özer, 2013). Bununla birlikte uzun zamandır fiziksel uygunluk hem spor performansını hem de sağlığı geliştiren önemli bir araç olarak görülmektedir (Winnick ve Porretta, 2016).

Kalp dolaşım uygunluğu (aerobik yeterlilik), kassal uygunluk (kassal dayanıklılık ve kas kuvveti), esneklik, beden kompozisyonu (beden yağ yüzdesi, BKI), biyokimyasal parametreler (HDL, LDL, Trigliserid) sağlıkla ilişkili fiziksel uygunluk unsurları, sürat (anaerobik kapasite), çabukluk, çeviklik, koordinasyon, patlayıcı kuvvet ise motor uygunluk unsurları arasında yer alır (Özer, 2013).

Yapılan birçok çalışmada engelli gençlerin fiziksel uygunlukları engelli olmayanların yaşıtları ile karşılaştırılmış ve bazı istisnalar dışında yetersizliği olan genç bireylerin fiziksel uygunluklarının engelli olmayan akranlarından daha düşük olduğu belirlenmiştir. Engelli gençlerin fiziksel uygunluklarının kabul edilebilir seviyelerin altına düşmesi durumunda, sağlık sorunları açısından engelli olmayan öğrencilere göre daha büyük risk altında olmaları muhtemeldir (Winnick ve Porretta, 2016). Fiziksel aktivite, iskelet kası tarafından üretilen herhangi bir bedensel hareket olarak tanımlanmakta ve dinlenme enerji harcamalarında önemli bir artışa neden olmaktadır. Bununla birlikte engelli olan ve olmayan bireylerin fiziksel uygunluklarını fiziksel aktivite yolu ile geliştirilebilecekleri ifade edilmektedir. Bu amaçla fiziksel aktivitelerin özellikle yetersizliği olan öğrenciler için uyarlanması ve aktivite şiddetinin iyi ayarlanması gerektiği belirtilmektedir (Winnick ve Porretta, 2016).

Bu araştırmanın amacı DS'li gençler ile NGG gençlerin fiziksel uygunluklarını karşılaştırarak incelemektir. Bu doğrultuda gerçekleştirilecek araştırma sonuçları DS'li bireylere yönelik fiziksel aktivite çalışmalarına daha fazla önem verilmesi konusunda katkı sağlayabilir. 


\section{Yöntem}

\section{Araştırmanın Modeli}

Katılımcılar üzerinde herhangi bir müdahale yapmadan gruplar arasındaki var olan farklılıkların nedenlerini ve sonuçlarını belirlemeyi amaçlayan çalışmalara nedensel karşılaştırma araştırması denir (Büyüköztürk ve ark., 2015). Bu doğrultuda DS'li ve NGG gençlerin fiziksel uygunluk düzeylerini herhangi bir müdahalede bulunmadan ölçüp karşılaştırmak amacıyla çalışmada nedensel karşılaştırma araştırması yöntemi kullanılmıştır.

\section{Evren ve Örneklem}

Katılımcıların belirlenmesinde kolayda örnekleme yöntemi kullanılmıştır. Batman Eğitim Uygulama Okulu ve özel eğitim ve rehabilitasyon merkezlerinde özel eğitim hizmetlerinden yararlanan13-17 yaş arasında bulunan 16 DS'li bireye (9 erkek, $7 \mathrm{kız}$ ) ulaşılmıştır. Karşılaştırma grubu ise iki lisede eğitim gören aileleri tarafından araştırmaya katılmalarına izin verilen yaşları 13-17 arasında olan ve tesadüfi örneklendirme yöntemi ile belirlenen 16 engelsiz çocuktan (12 erkek, 4 kIz) oluşmuştur. DS'li çocukların yaş ortalaması $(15,312 \pm 1,537)$, karşılaştırma grubunun yaş ortalaması $(14,562 \pm 1,152)$ 'dır. Yaşlar arasında istatistiksel olarak anlamlı bir fark bulunmamıştır.

\section{Verilerin Toplanması}

Ölçümlerde alanda en yaygın şekilde kullanıma sahip testlerden biri olan, Brockport Fiziksel Uygunluk Testi kullanılmıştır. Brockport Fiziksel Uygunluk Testi 27 test maddesini içermektedir. Bir bireyin fiziksel uygunluğunu değerlendirmek için genellikle 4-6 test yeterli görülmektedir. Brockport Fiziksel Uygunluk Testi 1993-1998 yılları arasında New York Devlet Üniversitesi Brockport özel eğitim ofisi ve rehabilitasyon servisi tarafından 10-17 yaş arası zihinsel engelli, görme engelli, spinal kord yaralanmaları, serebral palsi, doğuştan anomalisi olan ve ampütasyonu olan gençlerin sağlıkla ilişkili fiziksel uygunluklarının gelişimini desteklemek amacıyla geliştirilmiştir. Bu testlerinin amacı, engelli gençlerin, fiziksel profillerini belirleyerek eksik olan yönlerin giderilmesi, fiziksel aktivitelere katılabilmeleri ve bağımsız yaşayabilmeleri için gerekli vücut kompozisyonu, esneklik, dayanıklılık ve kuvvet parametrelerinin geliştirilmesidir (Winnick ve Porretta, 2016). 
Brockport Fiziksel Uygunluk Testi kapsamında zihinsel engelli bireyler için önerilen test maddeleri doğrultusunda; BKI, el kavrama kuvveti, omuz germe, gövde kaldırma, mekik testi kullanılmıştır. Aşağıda her bir ölçüm açıklanmıştır. Antropometrik Ölçümler; boy, ağırlık ve Beden Kütle Indeksini (BKI) kapsamaktadır.

Boy: Bedenin dik, topukların bitişik ve baş frankfort pozisyonundayken başın verteks noktası ile yer arasındaki mesafe duvar skalası ile ölçülerek kaydedilmiş̧ir.

Ağırık: Deneklerin üzerinde hafif bir giysi varken çıplak ayak ile 0.1 hassalıkta elektronik ağırık tartısı ile ölçülerek kaydedilmiştir.

BKi: Elde edilen ağırlığın, boy uzunluğunun karesine bölünmesiyle hesaplanmıştır.

El Kavrama Kuvveti (EKK): El dinamometresi ile ölçülmüştür. Ölçümde dinamometrenin tutma yeri deneğin eline göre ayarlanmıştır. Katııımc dinamometreyi tercih ettiği el ile olabildiğince güçlü bir şekilde sıkması istenmiştir. Sonuç kg cinsinden dinamometre okunarak kaydedilmiştir. Bir el için yapılan üç denemenin ortalaması alınmıştır.

Omuz germe: Ölçüm sırasında bireyden ayakta durur pozisyonda ölçüm alınacak el omuz üstünden sırta değecek şekilde geriye uzatması diğer eli ile de sırtından olacak şekilde ellerin kavuşması istenmiştir. İki el kavuştuğunda sonuç "+" olarak kavuşmadığında ise "-" olarak değerlendirme yapılmıştır.

Gövde Kaldırma: Ölçüm sırasında katıımcı minderin üzerine yüz üstü yatar pozisyonda tüm vücut yerle temas eder, eller uylukların altına yerleşmiş şekilde pozisyonlanmıştır. Katıımcıdan gövdesini yavaş ve kontrollü bir şekilde yukarıya kaldırması istenmiştir. Cetvel yardımı ile çene ve minder arasındaki mesafe ölçülmüştür. Minder ve öğrenci çenesi arasında kalan mesafe $30 \mathrm{~cm}$ 'nin üzerinde ise "+" altında ise "-“ olarak değerlendirme yapılmıştır. Katııımının ayaklarının yerden kalkmamasına dikkat edilmiştir.

Mekik Test: Kişi uygulamaya sırtüstü yatar pozisyonda, ellerini uyluklarının üst kısmına koymuş, bacakları dizlerden 90 derece bükülmüş ve ayak tabanları yere tam temas eder pozisyonda başlamıştır. Kalça ile ayak arasındaki mesafe $30.5 \mathrm{~cm}$. den fazla olmayacak şekildedir. Bir yardımcı, bireyin ayaklarına destek vererek, pozisyonun bozulmasını önlemiş ve "Başla" komutuyla, birey gövdesini, dirsekleri uyluklarına dokununcaya kadar kaldırmış ve başlangıç pozisyonuna dönmüştür. Geri dönüşte, ikinci bir gövde kaldırışı başlamadan önce, skapulanın inferior kısmı mindere dokunmuş olacak şekilde ölçümler alınmıştır. Bir deneme yaptırılmış ve uygun formda yapılan her bir mekik sayısı puan olarak kaydedilmiştir. 
Ölçümler spor salonunda yapılmıştır. Ölçümler sırasında her bir test maddesi için model olunmuş ve sözel olarak açıklanmıştır. Katılımcıların her bir test maddesi ile ilgili olarak birer deneme yapmaları sağlanmıştır. Her bir DS'li genç tüm testlerin uygulanması ortalama 8-9 dakika, NGG akranları için ortalama 4-5 dakika sürmüştür.

\section{Verilerin analizi}

Sonuçların değerlendirilmesinde SPSS 21.0 programı kullanılmıştır. İki grup arasındaki ilişkiyi incelemek için Mann-Whitney U Testi uygulanmıştır.

\section{Sınırlılıklar}

Bu araştırmaya 13-17 yaş arasında olan ikinci bir engelin eşlik etmediği DS'li 16 çocuk ve aynı yaşlarda aynı sayıda NGG çocuklar üzerinde yapıımıştır. Karşılaştırma grubu olarak ölçümler beden kütle indeksi, el kavrama kuvveti, omuz germe, gövde kaldırma, mekik testi parametreleriyle sınırlıdır. Her iki gruptaki katılımcıların cinsiyet yönünden eşit sayıda olmaması ve fiziksel aktiviteye katııı durumları ile ilgili olarak bilgi alınmaması sonuçların yorumlanmasını sınırlandırmaktadır.

\section{Bulgular}

DS'li gençlerin fiziksel uygunluklarını engelsiz akranları ile karşılaştırarak incelemek amacıyla gerçekleştirilen araştırma sonuçları aşağıda yer almaktadır.

Tablo 1. DS'li ve NGG katılımcıların fiziksel uygunluk sıra ortalamalarının karşılaştırılması

\begin{tabular}{|c|c|c|c|c|c|c|}
\hline Parametreler & Gruplar & $\mathbf{N}$ & Sira ort. & Sira Top. & $\mathbf{u}$ & p \\
\hline \multirow{2}{*}{ Beden-Kütle İndeksi } & DS & 16 & 21,72 & 339,50 & \multirow{2}{*}{52,50} & \multirow{2}{*}{,002 } \\
\hline & NGG & 16 & 11,28 & 188,50 & & \\
\hline \multirow{2}{*}{ El Kavrama Kuvveti } & DS & 16 & 8,63 & 138,00 & \multirow{2}{*}{$-2,00$} & \multirow{2}{*}{, 000} \\
\hline & NGG & 16 & 24,38 & 390,00 & & \\
\hline \multirow{2}{*}{ Omuz Germe } & DS & 16 & 10,50 & 168,00 & \multirow{2}{*}{32,00} & \multirow{2}{*}{, 000} \\
\hline & NGG & 16 & 22,50 & 360,00 & & \\
\hline \multirow{2}{*}{ Mekik Testi } & DS & 16 & 8,56 & 137,00 & \multirow{2}{*}{1,00} & \multirow{2}{*}{, 000} \\
\hline & NGG & 16 & 24,44 & 391,00 & & \\
\hline \multirow{2}{*}{ Gövde Kaldırma } & DS & 16 & 15,00 & 240,00 & \multirow{2}{*}{104,00} & \multirow{2}{*}{,151 } \\
\hline & NGG & 16 & 18,00 & 288,00 & & \\
\hline
\end{tabular}


Araştırma sonucuna göre; DS'li ve NGG gençler arasında BKI, EKK, omuz germe ve mekik testi değerleri yönünden istatistiksel olarak anlamlı farklılık bulunmuştur $(p<0,05)$. Ancak gövde kaldırma yönünden istatistiksel olarak anlamlı farklılık bulunamamıştır $(p>0,05)$.

Bu sonuçlara göre; DS'li gençlerin BKI (Sıra ort. $=21,22 \mathrm{~kg} / \mathrm{m}^{2}$ ) değerleri NGG gösteren gençlerin BKI (Sıra ort. $=11,78 \mathrm{~kg} / \mathrm{m}^{2}$ ) değerlerinden istatistiksel oalrak anlamlı düzeyde daha yüksek bulunmuştur $(p<.05)$. Diğer yandan; DS'li gençlerin EKK (Sıra ort. $=8,63 \mathrm{~kg})$, omuz germe (Sıra ort. $=10,50)$ ve mekik (Sıra ort. $=8,56)$ ortalamaları, NGG gençlerin EKK (Sıra ort.=24,38 kg), omuz germe (Sıra ort= 22,50) ve mekik (Sıra ort. $=24,44)$ ortalamalarından istatistiksel olarak anlamlı düzeyde daha düşük olduğu tespit edilmiştir. Diğer taraftan gövde kaldırma açısından karşıllaşıııılığında DS'li gençlerin ortalamaları (sıra ort. 15,00) NGG gençlerin ortalamalarından (sıra ort. 18,00) düşük olmaya eğilimli bulunmakla birlikte bu farklıık istatistiksel olarak anlamlı bulunmamıştır ( $p>.05)$.

\section{Tartışma ve Sonuç}

Bu araştırmanın amacı DS'li gençlerin fiziksel uygunluklarını engelsiz akranları ile karşıllaştırarak incelemektir.

DS'li gençlerin BKI ortalaması NGG gençlerin ortalamasından önemli derece daha yüksek bulunmuştur. Ayrıca National Heart Lung and Blood Institute (2019) tarafından belirlenen standartlarla karşılaştııılıı̆ında DS'li gençlerin BKI'leri incelendiğinde, dört kişi obez, dört kişi aşırı kilolu, beş kişi normal ve üç kişi zayıf olarak belirlenmiştir. Ayrıca NGG gençlerden sekiz kişinin zayıf ve sekiz kişinin ise normal BKi'lere sahip oldukları, aşırı kilolu veya obezitenin görülmediği ortaya konulmuştur (NIH, 2019). Çalışmamıza paralel olarak; Melville ve ark. (2005), DS'li bireylerde obezite görülme sıklığını inceledikleri çalışmalarında, DS'li kız ve erkeklerin, engeli olmayan akranlarına göre, boy uzunluğu açısından daha düşük değerlere sahip olduğunu saptamışlardır. Kız DS'lilerin BKI ortalamasının ise; engeli olmayan hem cinslerine göre daha yüksek olduğunu, yani obezite görülme sıklığının kız DS'lilerde anlamlı olarak daha fazla olduğunu belirtmişlerdir. Erkek DS'lilerin ise engeli olmayan akranlarına göre BKİ ortalamasının yüksek olduğu, ancak aralarında istatistiksel olarak anlamlı bir farklılık olmadığı için, DS'li erkeklerin akranlarına göre obezite eğiliminde oldukları sonucuna varılmıştır (Melville ve ark., 2005). Bununla birlikte Gonzales ve Aguero (2010), DS'li bireylerin, zihinsel engelli akranlarına ve engeli olmayan akranlarına göre daha fazla sağlık sorunlarına sahip olmaları ve 
ebeveynleri tarafından aşırı koruyucu tutumla karşılaşmaları nedeni ile fiziksel aktivitelere ve spora daha az katılım gösterdiklerini ileri sürmektedirler.

DS'li bireylerin EKK ortalaması NGG akranları ile karşılaştırıldıklarında önemli derece daha düşük bulunmuştur. DS'li çocuklarda görülen hipotoni, ince motor becerilerin gecikmesinin önemli bir sebebidir. Kol ve el kaslarında görülen hipotoni, nesneleri tutmak, büyük bir düğmeye basmak gibi basit eylemleri dahi zorlaştırır. Ayrıca DS'li bireylerin sahip oldukları küçük el ve küçük parmaklar, büyük nesnelerin kavranması ve tutulmasının yanı sıra, gitar çalmak, bilgisayar kullanmak gibi koordinasyon ve beceri gerektiren aktivitelerin yapılmasını da zorlaştırabilir (Bruni, 1998). Spano ve ark. (1999), kaba ve ince motor becerilerini değerlendirdiği 22 DS'li çocuğun becerilerinin kronolojik yaşlarının gerisinde olduğunu, ince motor becerilerin kaba motor becerilere kıyasla daha geri olduğunu ve erken eğitim alan çocukların elde ettikleri değerlerin daha iyi olduğunu bildirmişlerdir. Bunun yanında Chen ve ark. (2014) tarafından yapılan bir çalışmada DS'li genç erkeklerde BKİ ve bel çevresi gibi antropometrik faktörler ile EKK arasında ilişki olduğu bulunmuştur. Bu çalışmada ayrıca, tek bir egzersiz seansından sonra bile EKK'de iyileşme olduğu saptanmıştır.

DS'li gençlerin omuz germe testini yapabilme oranları NGG akranlarının oranlarına göre anlamlı düzeyde düşük bulunmuştur. Terblanch ve Boer (2013) DS'lilerde görülen fazla kilolar ve kısa kolların omuz germe hareketini yapma yeteneklerini engelleyebileceğini bildirmişleridir.

DS'li bireylerin mekik testi ortalaması normal gelişim gösteren bireylerin ortalamasından önemli derece daha düşük bulunmuştur. Literatürde DS'li bireylerin özellikle motor becerilerde, engeli olan ve olmayan akranlarına göre daha geride oldukları ve DS'li bireylerin motor becerilerinin gelişimi için fiziksel aktivite ve spora katılımlarının son derece önemli olduğu bildirilmektedir (Fidler ve ark., 2005; Jobling ve Virji-Babul, 2004).

Gövde kaldırma performansı yönünden, DS'li gençler ile NGG akranları arasında anlamlı bir farklılık bulunmamıştır. Buna rağmen katılımcılar arasında DS'li gençler arasında dört kişi NGG gençler arasından ise sadece bir kişi bu testi başarı ile tamamlayamamıştır. Terblanch ve Boer (2013), yaptıkları araştırmada 45 yaş üstü DS'li bireylerin genel popülasyon ile karşılaştırılığında gövde kaldırma özelliğinin de içinde bulunduğu fiziksel uygunluk özellikleri bakımından düşük seviyeye sahip olduklarını belirtmiştir. Ayrıca gövde kaldırma hareketinin gövde kuvvetini ölçtüğünü bunun da günlük fonksiyonel görevlerin yapılmasında önemli katkısının olduğunu ifade etmişlerdir. Bununla birlikte Winnick ve Porretta (2016), DS'li bireylerde beden 
eğitimi programı yapılırken özellikle eklemlerin etrafındaki kasların kuvvetlendirilerek eklemlerin stabilizasyonunu sağlayan etkinlik ve egzersizlere yönelmeleri gerektiği üzerinde durmuşlardır.

Sonuç olarak; NGG akranları karşılaştırıldığında DS'li gençlerin BKI'nin yüksek olduğu, EKK, gövde kaldırma ve mekik özellikleri yönünden ise daha düşük değerlere sahip oldukları bulunmuştur. Bu bulgular literatür bilgileri ve önceki araştırmalarla tutarlılık göstermektedir. DS'li bireylerin fiziksel uygunluk yönünden yetersiz olmaları biyolojik ve çevresel (aktiviteye katılma, öğretim, teşvik ve cesaretlendirme) dezavantajlardan kaynaklanabileceği düşünülmektedir. Bu araştırmanın sonuçlarına göre, DS'li çocuk ve gençlerin hem eğitim aldıkları kurumlarda hem de okul dışı zamanlarda fiziksel aktivite programlarına katıımlarının sağlanması ve fiziksel uygunluklarını arttırmaya yönelik çalışmaların yapılması önerilmektedir. Bu bağlamda ailelerin bilinçlendirimesi, okuldaki beden eğitimi dersi olanaklarının arttırılması ve belediyelerin spor olanaklarından faydalanabilmeleri önem kazanmaktadır. Kuşkusuz tüm bu süreçte DS'li çocuk ile gençlerin fiziksel uygunluklarının değerlendirmesi, izlenmesi ve bireyselleştirilmiş beden eğitimi programlarının temel alınması önem kazanmaktadır.

\section{Kaynaklar}

Ali, F. E., Al-Bustan, M. A., Al-Busairi, W. A., Al-Mulla, F. A., Esbaita, E. Y. (2006). Cervical spine abnormalities associated with Down syndrome. International orthopaedics, 30(4), 284-289.

Bruni M. (1998). Fine motor skills in children with Down syndrome: A guide for parents and professionals. Woodbine House.

Büyüköztürk Ş, Akgün ÖE, Demirel F, Karadeniz Ş, Çakmak EK. (2015). Bilimsel araştırma yöntemleri. Ankara: Pegem Akademi.

Chen, C. C. J., Ringenbach, D. R. S., Snow, M. (2014). Treadmill walking effects on grip strength in young men with Down syndrome. Research in Developmental Disabilities, 35(2), 288-293.

Cohen WI, Nadel L, Madnick ME. (2003) Down syndrome: visions for the 21st century. John Wiley \& Sons.

Fidler, D. J., Hepburn, S. L., Mankin, G., Rogers, S. J. (2005). Praxis skills in young children with Down syndrome, other developmental disabilities, and typically developing children. The American journal of occupational therapy, 59(2), 129-138. 
González-Agüero, A., Vicente-Rodríguez, G., Moreno, L. A., Guerra-Balic, M., Ara, I., Casajus, J. A. (2010). Health-related physical fitness in children and adolescents with Down syndrome and response to training. Scandinavian journal of medicine \& science in sports, 20(5), 716-724.

Jobling, A. (1998). Motor development in school-aged children with Down syndrome: a longitudinal perspective. International Journal of Disability, Development and Education, 45(3), 283-293.

Jobling A, Virji-Babul N. (2004). Down syndrome: Play, move and grow. Down Syndrome Research Foundation Burnaby, BC, Canada.

Kamil, Ö. (2013). Fiziksel Uygunluk. Nobel Yayınları, 4. Basım, Ankara.

Lauteslager PE. (2004). Children with Down's Syndrome: Motor Development and Intervention. Heeren Loo Zorggroep.

Määttä, T., Kaski, M., Taanila, A., Keinänen-Kiukaanniemi, S., livanainen, M. (2006). Sensory impairments and health concerns related to the degree of intellectual disability in people with Down syndrome. Down Syndrome Research and Practice, 11(2), 78-83.

Melville, C. A., Cooper, S. A., McGrother, C. W., Thorp, C. F., Collacott, R. (2005). Obesity in adults with Down syndrome: a case-control study. Journal of Intellectual Disability Research, 49(2), 125-133.

Özer K. (2013). Fiziksel uygunluk. Ankara: Nobel Yayın Dağıtım; 2013.

Schieve, L. A., Boulet, S. L., Boyle, C., Rasmussen, S. A., Schendel, D. (2009). Health of children 3 to 17 years of age with Down syndrome in the 1997-2005 national health interview survey. Pediatrics, 123(2), e253.

Spanò, M., Mercuri, E., Randò, T., Pantò, T., Gagliano, A., Henderson, S., Guzetta, F. (1999). Motor and perceptual-motor competence in children with Down syndrome: variation in performance with age. European Journal of Paediatric Neurology, 3(1), 7-14.

Terblanche, E., Boer, P. H. (2013). The functional fitness capacity of adults with Down syndrome in South Africa. Journal of Intellectual Disability Research, 57(9), 826-836.

Winders, P. (1997). Gross motor skills in children with down syndrome: a guide for parents and professionals (topics in Down syndrome). Woodbine House, Bethesda (MD).

Winnick J, Porretta D. (2016). Adapted Physical Education and Sport, 6E. Human Kinetics; 2016. 


\section{İnternet Kaynakları}

https://www.ndss.org/about-down-syndrome/down-syndrome/. National Down Syndrome Society. About Down Syndrome; Erişim Tarihi: 21.03.2019.

https://www.cdc.gov/ncbddd/birthdefects/DownSyndrome.html. Centers for Disease Control and Prevention. _Erişim Tarihi: 21.03.2019.

https://www.nhlbi.nih.gov/health/educational/lose_wt/BMI/bmicalc.html. National Heart Lung and Blood Institute. Erişim Tarihi: 22.04.2019. 